\title{
Perception of Effects of Shiftwork Questionnaire (PESQ) among Ambulance Service Staff in Saudi Arabia: An Exploratory Factor Analysis
}

\author{
Fawaz Albishri, Loay Zamzami \\ Department of Emergency Medicine, King Abdullah Medical City, Makkah, Saudi Arabia \\ Email: fawazd1000@yahoo.com
}

How to cite this paper: Albishri, F. and Zamzami, L. (2021) Perception of Effects of Shiftwork Questionnaire (PESQ) among Ambulance Service Staff in Saudi Arabia: An Exploratory Factor Analysis. Open Journal of Emergency Medicine, 9, 123-134. https://doi.org/10.4236/ojem.2021.93012

Received: July 19, 2021

Accepted: September 3, 2021

Published: September 6, 2021

Copyright $\odot 2021$ by author(s) and Scientific Research Publishing Inc. This work is licensed under the Creative Commons Attribution International License (CC BY 4.0).

http://creativecommons.org/licenses/by/4.0/

\section{(c) (i) Open Access}

\begin{abstract}
Objective: Despite efforts in describing the impact of shiftwork on the performance of health care workers, the perception of ambulance service staff is largely unexplored. This study attempted to develop the Perception of Effects of Shiftwork Questionnaire (PESQ) using a factor analysis approach to determine the underlying dimensions. Methods: A 16-item Likert scale research instrument, designed to gather information about the perceived effects of shiftwork on the respondents' health, social relationships, and career quality, was floated to 375 ambulance services personnel in Saudi Arabia during March and April 2021. Results: Based on factor analysis, the questionnaire has three dimensions with varying reliability, namely "perceived effects on social relationship" ( $\alpha=0.815)$, perceived effects on health $(\alpha=0.787)$ and "perceived effects on career quality" ( $\alpha=0.602)$. Over-all, the research instrument had an acceptable internal consistency ( $\alpha=0.829)$. Conclusion: The three-dimension model was analyzed simultaneously using parallel analysis and confirms that the three-factor model is the most ideal for the research instrument. Further research, however, is recommended to improve the internal consistency of the items which measure the perceived effects on career quality.
\end{abstract}

\section{Keywords}

Shiftwork, Ambulance Staff, Ambulance Staff Wellbeing, Staff Performance, Factor Analysis

\section{Introduction}

Shiftwork is common in industries which require the availability or continuity of various services in 24 hours [1]. Conventionally, shift work involves working 
outside daytime working hours or on a schedule other than the standard working week and may involve changes in working time arrangements. In most cases, shiftwork in the workplace involves changes in areas of deployment, rotation patterns and schedule [2] [3] [4] [5]. Due to an increasing demand for healthcare services, healthcare systems have required doctors, nurses and other health care professionals to engage in shiftwork to ensure continuity of medical services in clinical settings, emergency cases and rescue operations [2] [4] [6] [7].

Shiftwork is perceived to be indispensable due to globalization as it ensures continuity of essential services. The implementation of shiftwork has been common predominantly in Western countries [8]. Currently, studies which describe the effects of shiftwork to health professionals have been explored, revealing a negative effect on their over-all well-being [3] [5] [9]. During night shifts, in particular, health care workers need to be awake during a time when behavioral inactivity is expected [10]. Most studies dealt with the effects of night shift on the short-term physical and mental well-being of health care professionals and effects on social relationships. Other studies have reported an increased propensity of individuals to develop chronic conditions such as cancer, cardiovascular diseases and diabetes [2] [4] [10]-[15].

Members of ambulance services experience a unique working environment compared to other healthcare professionals in the clinical setting. Aside from dealing with unpredictable cases which require a diverse skill set to provide prehospital interventions, the cases are usually highly stressful especially during night shift, since precise management of pharmacological interventions and clinical skills need to be ensured [16]. When individuals work at night, exposure to light and physical activity causes a disturbance of circadian rhythms, leading to decreased cognitive functions, stress and anxiety [4] [6] [9] [14] [17]. In addition to shift work, ambulance service staff have to cope with other issues such as trauma, accidents, and death, which makes them susceptible to mental health problems [16].

There have been few efforts to investigate the effects of shiftwork on ambulance service staff and personnel using physiologic parameters in other countries, but the social and psychological components remain unexplored [7] [16]. Previous studies have used single-construct questionnaires to evaluate the psychological effects of shiftwork such as the Standard Shift Work Index which measures self-report impact of work on the health and well-being of individuals and General Health Questionnaire (GHQ-28) which measures general well-being [4]. [18] However, there has been no effort to capture the perceived total effects of shiftwork on the over-all wellbeing of ambulance service staff and personnel in Saudi Arabia or other Middle Eastern countries, which has robust psychometric properties. While other countries present rich information on the various effects of shift work in Western ambulance service staff, the effects of shiftwork to ambulance staff in Saudi Arabia remains unexplored, although efforts have been 
done to determine the effects shiftwork on nurses in Saudi Arabian clinical settings [19].

The rules and regulations of occupational health and safety in Saudi Arabia are emerging, and the need for globalization and standardization of policies need to be addressed since there are limited literature which can support the similarities of ambulance services in Western and Middle Eastern contexts [16]. In order to capture the over-all effects of shiftwork to the ambulance service staff in Saudi Arabia, there is a need to construct a research instrument which integrates various aspects which were reported to be affected by shiftwork based on the currently available literature. Hence, this study aimed to develop a research instrument which can measure the effects of shiftwork to various dimensions of well-being among ambulance service staff in Saudi Arabia.

\section{Materials and Methods}

\subsection{Research Instrument}

The analyzed instrument is the Perception of Effects of Shiftwork Questionnaire (PESQ). The research instrument is a Likert-scale questionnaire, composed of 16 items which are designed to gather information about the perceived effects of night shift to the respondents' health, social relationships, and career quality. One item, Q14, determines which shift the respondents will most likely make a wrong decision.

\subsection{Validity}

To determine the instrument validity, the questionnaire was presented to three experts in the field of research and occupational health. The experts were asked to express their views about relevance, necessity and clarity of the questions. Inputs and feedback received from the experts were included while finalizing the questionnaire.

\subsection{Inclusion, Exclusion and Withdrawal Criteria}

The inclusion criteria of participants in the present study were as follows: 1) currently employed emergency medical staff, 2) male or female, 3) works in ambulance services, and 4) actively participates in shiftwork. Staff performing administrative work, drivers, volunteers and those working in part-time positions were excluded. All respondents who have withdrawn from answering the questionnaire were excluded from the analysis of data.

\subsection{Process}

The research instrument was completed by 375 respondents who received an online link to an electronic version of the research instrument via email and social media tools. All research participants were adults who had experience in doing night shift. Participation was voluntary and complied with the rules of informed consent. 


\subsection{Data Analysis}

Exploratory factor analysis was conducted to determine the underlying constructs of the study. Exploratory factor analysis is a statistical method employed to increase the reliability of the scale by identifying inappropriate items that can be removed and the dimensionality of constructs by examining the existence of relationships between items and factors when the information of the dimensionality is limited [20].

To determine the correlations between the items in the identity matrix and determine the suitability of using factor analysis, Bartlett's sphericity test and Kaiser-Meyer-Olkin Test were performed. The degree of deviation from scores from the normal distribution was analyzed by examining asymmetry and kurtosis. Exploratory factor analysis was performed using principal axis factoring with Varimax rotation. This extraction method is more appropriate to determine the underlying constructs in this study. Parallel analysis was also conducted to determine the break in the Scree plot using the syntax [21]. Several random samples based on the actual data are generated, and for each random sample, the parallel analysis procedure calculates eigenvalues [22]. Cronbach's alpha values were used to estimate the reliability of the over-all instrument and of each of the considered dimensions.

\section{Results}

\subsection{Demographic Characteristics}

Table 1 shows that out of 357 respondents, more than $77 \%$ were male professionals. More than half of the respondents are aged between 20 to 30 years old. Most of the respondents (56.0\%) had experience ranging from 5 to 10 years and were married (61.6\%). Most respondents finished a bachelor's degree or diploma degree (cumulative $82.9 \%$ ).

\subsection{Item Description}

Table 2 summarizes the central tendency statistics and the forms of the items that compose the evaluation instrument. Based on the results, the data is platykurtic and has negative skew. Based on Shapiro-Wilk's test, the data is not normally distributed. The highest mean was observed in item Q3 (I have more sleeping problems when working night shift compared to when I work day shift) while the lowest mean was observed in item Q15 (Working in shift gives me the opportunity to improve my performance and advance in my career). Over-all, the standard deviations ranged from 1.25 to 1.43. In item Q14, respondents reported that they are most likely to make wrong decisions during night shift (72.30\%, Figure 1).

\subsection{Data Suitableness for Factor Analysis}

The results for goodness of fit for exploratory factor analysis using principal axis factoring revealed that Kaiser's Measure of Sampling Adequacy value was 0.888 
and Bartlett's Test of Sphericity value was $1620.916(\mathrm{df}=120, \mathrm{p}<0.001)$, indicating that the data were suitable for factor analysis.

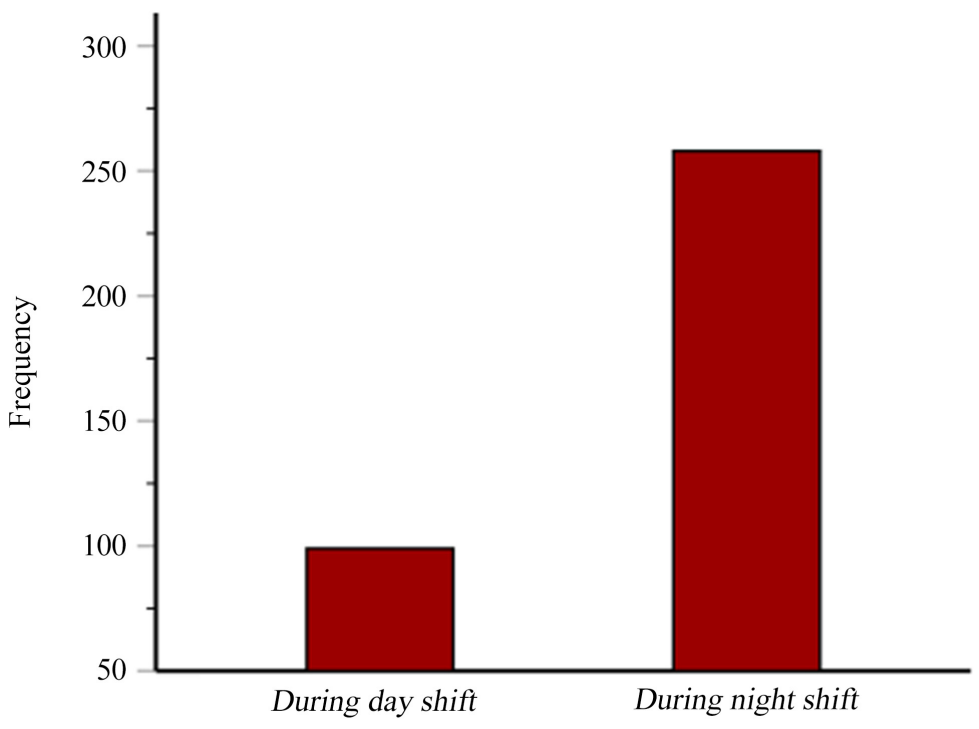

Q14: When do you think are you most likely to make a wrong decision?

Figure 1. Perceived likelihood of committing wrong decision.

Table 1. Descriptive statistics of demographic variables $(n=357)$.

\begin{tabular}{|c|c|c|c|}
\hline \multicolumn{2}{|c|}{ Demographic Factors } & $\mathbf{N}$ & $\%$ \\
\hline \multirow{2}{*}{ Gender } & Male & 276 & $77.3 \%$ \\
\hline & Female & 81 & $22.7 \%$ \\
\hline \multirow{4}{*}{ Age } & Younger than 20 years old & 16 & $4.5 \%$ \\
\hline & Between 20 and 30 years old & 203 & $56.9 \%$ \\
\hline & Between 31 and 40 years old & 122 & $34.2 \%$ \\
\hline & Above 41 years old & 16 & $4.5 \%$ \\
\hline \multirow{3}{*}{ Duration of Shift Work } & Less than 5 years & 82 & $23.0 \%$ \\
\hline & One to five years & 161 & $45.1 \%$ \\
\hline & More than five years & 114 & $31.9 \%$ \\
\hline \multirow{2}{*}{ Marital Status } & Not married & 137 & $38.4 \%$ \\
\hline & Married & 220 & $61.6 \%$ \\
\hline \multirow{4}{*}{ Work Experience } & Less than one year & 75 & $21.0 \%$ \\
\hline & Between 5 and 10 years & 200 & $56.0 \%$ \\
\hline & Between 10 and 15 years & 61 & $17.1 \%$ \\
\hline & More than 20 years & 21 & $5.9 \%$ \\
\hline \multirow{4}{*}{ Educational Background } & Diploma & 144 & $40.3 \%$ \\
\hline & Bachelor & 152 & $42.6 \%$ \\
\hline & Post Graduate Diploma or Master & 28 & $7.8 \%$ \\
\hline & Doctor of Philosophy & 33 & $9.2 \%$ \\
\hline
\end{tabular}


Table 2. Item descriptive statistics of Perception of Effects of Shiftwork Questionnaire (PESQ).

\begin{tabular}{|c|c|c|c|c|c|}
\hline $\begin{array}{l}\text { Item } \\
\text { Number }\end{array}$ & Statements & Mean & $\begin{array}{l}\text { Standard } \\
\text { Deviation }\end{array}$ & Skewness & Kurtosis \\
\hline Q01 & I experience more health issues when working during night shift. & 3.85 & 1.25 & -0.95 & -0.36 \\
\hline Q02 & I feel more stressed working during a night shift. & 3.63 & 1.32 & -0.70 & -0.87 \\
\hline Q03 & I experience sleeping problems when working during night shift. & 3.98 & 1.30 & -1.08 & -0.23 \\
\hline Q04 & I cannot control my weight because of the shift work system. & 3.64 & 1.42 & -0.73 & -0.95 \\
\hline Q05 & I have poor social relationship because of my shift work. & 3.67 & 1.38 & -0.61 & -1.15 \\
\hline Q06 & Night shift causes conflict with my family. & 3.56 & 1.40 & -0.62 & -1.07 \\
\hline Q07 & Night shift has a negative impact in the relationship with my children & 3.62 & 1.23 & -0.50 & -0.87 \\
\hline Q08 & Due to work shift, I am unable to maintain social relationships. & 3.95 & 1.27 & -1.16 & 0.10 \\
\hline Q09 & While working the night shift, I do not have enough social support and services for my family. & 3.85 & 1.38 & -0.93 & -0.60 \\
\hline Q10 & A night shift work causes me to spend less time with my family. & 3.87 & 1.33 & -0.91 & -0.60 \\
\hline Q11 & $\begin{array}{l}\text { Because of the night shift work, I feel that I am not fully fulfilling my responsibilities towards } \\
\text { my family. }\end{array}$ & 3.94 & 1.27 & -1.04 & -0.22 \\
\hline Q12 & My quality of work in the night shift does not differ from my quality of work in the day shift. & 3.46 & 1.41 & -0.39 & -1.36 \\
\hline Q13 & I feel tired after midnight while working with patients at night. & 3.62 & 1.37 & -0.62 & -1.05 \\
\hline Q15 & $\begin{array}{l}\text { Working during a night shift gives me opportunity to improve my performance and advance } \\
\text { my career. }\end{array}$ & 3.07 & 1.43 & -0.04 & -1.51 \\
\hline Q16 & I feel sleepier after working during my night shift. & 3.85 & 1.27 & -1.05 & -0.11 \\
\hline
\end{tabular}

\subsection{Factor Analysis Results}

Principal axis factoring with Varimax rotation was utilized to determine the factor structure of the research instrument. The scree plot in Figure 1 shows that the break point was observed after the third dimension, indicating that that the research instrument has three underlying dimensions. The first factor has an eigenvalue of 5.108, while the second and third factors had 1.538 and 1.217 eigenvalues, respectively Figure 2 .

Factor 1 (perceived effects on social relationship) explained $34.05 \%$ of the variance. On the other hand, Factor 2 (perceived effects on health) and Factor 3 (perceived effects on career quality) explained $10.256 \%$ and $8.117 \%$ of the variance, respectively. Over-all, the three factors explained $52.423 \%$ of the observed variance. Based on Cronbach alpha results, internal consistency for Factor $1(\alpha=0.815)$ and Factor $2(\alpha=0.787)$ were adequate, but the internal consistency for Factor $3(\alpha=0.602)$ was considered questionable. Over-all, the research instrument had an acceptable internal consistency $(\alpha=0.829)$.

\subsection{Factor Loading}

Table 3 shows the factor loadings for each item of the Perception of Effects of Shiftwork Questionnaire (PESQ). Using a cut point of $|0.40|$, seven items (Q5, Q6, Q7, Q8, Q9, Q10, Q11) loaded into Factor 1, another six items loaded into Factor $2(\mathrm{Q} 01, \mathrm{Q} 02, \mathrm{Q} 03, \mathrm{Q} 04, \mathrm{Q13}, \mathrm{Q} 16)$, while only two items loaded into 
Factor 3 (Q12, Q15). No items loaded onto more than two factors. In Factor 1, the range of loading factors was 0.448 to 0.675 , while in Factor 2, the range of factor loading was between 0.430 to 0.682 . The range of factor loading in Factor 3 was 0.544 to 0.771 .

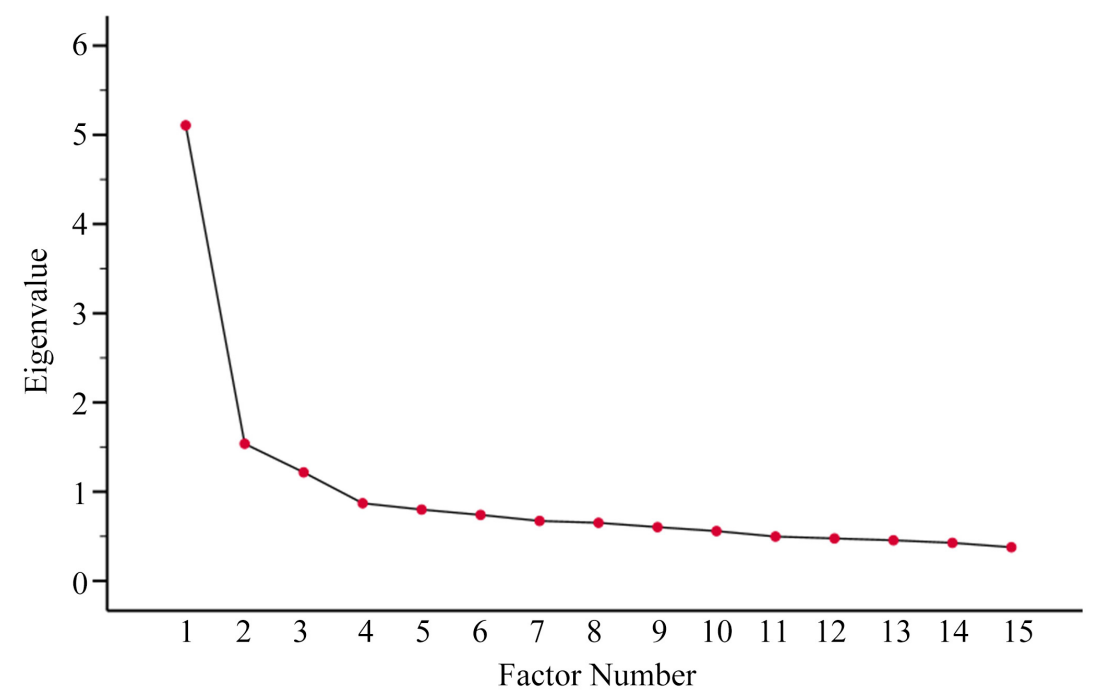

Figure 2. Scree plot showing distribution of factors by their eigenvalues.

Table 3. Factor loading of items in PESQ (Extraction Method: Principal Axis Factoring. Rotation Method: Varimax with Kaiser Normalization Rotation converged in 5 iterations).

\begin{tabular}{lccc}
\hline & & Factor & 3 \\
\hline Qtem & 1 & 2 & \\
\cline { 2 - 4 } Q08 & 0.675 & & \\
Q09 & 0.666 & & \\
Q11 & 0.629 & & \\
Q07 & 0.580 & & \\
Q05 & 0.480 & & \\
Q06 & 0.466 & & \\
Q02 & 0.448 & 0.544 \\
Q03 & & 0.682 & \\
Q01 & & 0.587 & \\
Q13 & & 0.558 & \\
Q04 & & & \\
Q16 & & 0.506 & \\
Q15 & & & \\
Q12 & & & \\
\hline & & & \\
\hline
\end{tabular}




\section{Discussion}

The primary objective of this study is to determine the factor structure of the PESQ in light of the perceived effects of a night shift to the ambulance services staff in Saudi Arabia. The present results reveal a three-factor solution for the research instrument, which generally presented a good fit to the data. The three-factor structure of the research instrument included the perceived effects on health, social relationship and career quality. With regards to the over-all internal consistency, PESQ has a satisfactory Cronbach alpha, but the dimension pertaining to "perceived effects on career quality" needs to be re-evaluated. To the author's knowledge, this is the first attempt to develop a questionnaire which addresses the perceived effects of night shift to the over-all health, social relationship and career quality among emergency medical service staff in Saudi Arabia.

An extensive body of literature has explored the effects of a night shift to sleep quality (Farias et al.; Khan et al.; Vetter et al.), physical health (Ferri et al.; Nea et al.), mental health and psychological well-being (Ferri et al.; Khan et al.; Suminska et al.), social relationship (Grzywacz; Iskra-Golec et al.; Tai et al.), work performance (Costa; Dehring et al.; Recio-Saucedo et al.), cognitive function (Suminska et al.), and predisposition to unhealthy lifestyle (Shan et al.), certain types of cancer (Szkiela et al:; Yuan et al.), diabetes, and cardiovascular diseases (Strohmaier et al.) [2] [4] [7] [8] [10] [12] [13] [15] [16] [17] [23] [24]. Furthermore, health professionals who worked during night shifts were reported to exhibit more mental health problems such as irritability, somatization, obsessive-compulsive disorder, interpersonal sensitivity, anxiety, altered mood, and paranoid disorders. While such issues have been assessed in clinical settings, there a dearth of literature on the assessment of the perception of ambulance medical services staff in Saudi Arabia [4].

In addition, the nature of work of ambulance service staff differs from health care professionals in clinical settings as the former deal with pre-hospital or post-hospital environments [25]. Furthermore, the cases dealt with ambulance services may be life-threatening and require an extensive use of available equipment inside the ambulance van prior to the provision of medical services in hospitals. Hence, being in a night shift providing ambulance services demand high proficiency, resourcefulness, and high cognitive function to make important decisions which ensure patient safety prior to the arrival to well-equipped hospitals.

Emergency services during night shift, however, induces high levels of physical and mental stress which may be caused by traumatic experiences or failure to address distresses during work [8]. Aside from the mental effects, shift works impairs eating patterns circadian rhythms which were often attributed as causes of work-related pathologies [9] [14] [17]. The development of a questionnaire which addresses the need for determining the perception of ambulance medical services has been fueled with this gap in literature.

The exploratory factorial validity using the factor extraction strategy used in 
this study, pertaining to principal axis factoring with Varimax rotation has satisfactorily identified the three dimensions which can be measured simultaneously in the Perception of Effects of Shiftwork Questionnaire (PESQ), which is contextualized to the ambulance service staff of Saudi Arabia. It has been observed that the dimension "perceived effects on social relationship" has the greatest contribution to the observed variance in the study. This implies that the effects of shiftwork to social relationship such as relationship to family members, lack of time to perform social tasks and strengthen social relationships is the greatest advocacy of PESQ. This validates other studies that social relationship is a commonly affected component of a health care worker's well-being [10] [21].

The second greatest source of variance was contributed by the dimension "perceived effects on health". Compared to other studies, the items in the research instrument describes generic issues related to over-all health. Apparently, issues on sleeping problems, weight gain, fatigue and feelings of tiredness belong to one factor, indicating a high correlation of the identified sub-components. This supports the effect of shiftwork to previously identified components of over-all wellbeing such as sleep quality (Farias et al.; Khan et al.; Vetter et al.) and physical health (Ferri et al.; Nea et al.) [2] [4] [8] [16] [17]. One limitation of the items in this dimension, however, is the lack of support for describing the effects to mental health and psychological well-being as reported by Ferri et al., Khan et al. and Suminska et al. [4] [7] [16].

One novel finding in this study is the inclusion of the perceived effects on quality of work (Q12) and career advancement (Q15). These two items are unique as no studies so far has explored the effects of shift work in the career trajectory of ambulance service staff. However, the third dimension (perceived effects on career quality) needs to be improved due to its low internal consistency. Nevertheless, this dimension contributes to the over-all internal consistency of the PESQ, which might further necessitate future investigation.

This study has several implications to the development of policies which will protect the over-all wellbeing of ambulance service staff and address the perceived effects to over-all health, social relationship and career quality among emergency medical service staff in Saudi Arabia. Other countries can also adapt the questionnaire for cross-cultural comparisons among Middle Eastern contexts.

\section{Conclusion}

This study contributes to the present work related to the exploration of the effects of shiftwork on the over-all wellbeing of ambulance service staff in Saudi Arabia. The research instrument developed in this study, Perception of Effects of Shiftwork Questionnaire (PESQ), has adequate reliability to measure the perception of effects of shiftwork on over-all health, social relationship, and career trajectory. Hence, the research instrument has the potential to be used to generate policies in improving the work schedule and improve the coping mechanisms of ambulance service staff in Saudi Arabia and in other Middle Eastern countries. 


\section{Ethics Approval and Consent to Participate}

The research protocol was approved by the Institutional Review Board at King Abdullah Medical City, Saudi Arabia, (ethics certificate number IRB Number 21-778). Informed consent was obtained from all participants and anonymity was ensured by assigning a code for each respondent.

\section{Availability of Data and Materials}

The data used in this study are available and can be provided on a reasonable request by the corresponding author.

\section{Authors' Contributions}

All authors involved in data collection, data interpretation, and manuscript drafting and approval.

\section{Conflicts of Interest}

The authors declare no conflicts of interest regarding the publication of this paper.

\section{References}

[1] Brachet, T., David, G. and Duseja, R. (2010) The Effect of Shift Structure on Performance: The Role of Fatigue for Paramedics. National Bureau of Economic Research, Cambridge. https://doi.org/10.3386/w16418

[2] Nea, F.M., Kearney, J., Livingstone, M.B., Pourshahidi, L.K. and Corish, C.A. (2015) Dietary and Lifestyle Habits and the Associated Health Risks in Shift Workers. $\mathrm{Nu}$ trition Research Reviews, 28, 143-166. https://doi.org/10.1017/S095442241500013X

[3] Costa, G. (2010) Shift Work and Health: Current Problems and Preventive Actions. Safety and Health at Work, 1, 112-123. https://doi.org/10.5491/SHAW.2010.1.2.112

[4] Ferri, P., Guadi, M., Marcheselli, L., Balduzzi, S., Magnani, D. and Di Lorenzo, R. (2016) The Impact of Shift Work on the Psychological and Physical Health of Nurses in a General Hospital: A Comparison between Rotating Night Shifts and Day Shifts. Risk Management and Healthcare Policy, 2016, 203-211. https://doi.org/10.2147/RMHP.S115326

[5] Kim, W., Kim, T.H., Lee, T.H., Choi, J.W. and Park, E.C. (2016) The Impact of Shift and Night Work on Health Related Quality of Life of Working Women: Findings from the Korea Health Panel. Health and Quality of Life Outcomes, 14, Article No. 162. https://doi.org/10.1186/s12955-016-0564-X

[6] Sofianopoulos, S., Williams, B. and Archer, F. (2012) Paramedics and the Effects of Shift Work on Sleep: A Literature Review. Emergency Medicine Journal, 29, 152-155. https://doi.org/10.1136/emj.2010.094342

[7] Sumińska, S., Nowak, K., Łukomska, B. and Cygan, H.B. (2020) Cognitive Functions of Shift Workers: Paramedics and Firefighters-An Electroencephalography Study. International Journal of Occupational Safety and Ergonomics, 27, 686-697.

[8] Farías, R., Sepúlveda, A. and Chamorro, R. (2020) Impact of Shift Work on the Eating Pattern, Physical Activity and Daytime Sleepiness among Chilean Healthcare Workers. Safety and Health at Work, 11, 367-371. https://doi.org/10.1016/j.shaw.2020.07.002 
[9] Lawn, S., Roberts, L., Willis, E., Couzner, L., Mohammadi, L. and Goble, E. (2020) The Effects of Emergency Medical Service Work on the Psychological, Physical, and Social Well-Being of Ambulance Personnel: A Systematic Review of Qualitative Research. BMC Psychiatry, 20, Article No. 348.

https://doi.org/10.1186/s12888-020-02752-4

[10] Tai, S.Y., Lin, P.C., Chen, Y.M., Hung, H.C., Pan, C.H., Pan, S.M., Lee, C.Y., Huang, C.T. and Wu, M.T. (2014) Effects of Marital Status and Shift Work on Family Function among Registered Nurses. Industrial Health, 52, 296-303.

[11] Recio-Saucedo, A., Maruotti, A., Griffiths, P., Smith, G.B., Meredith, P., Westwood, G., Fogg, C. and Schmidt, P. (2018) Relationships between Healthcare Staff Characteristics and the Conduct of Vital Signs Observations at Night: Results of a Survey and Factor Analysis. Nursing Open, 5, 621-633. https://doi.org/10.1002/nop2.179

[12] Shan, Z., Li, Y., Zong, G., Guo, Y., Li, J., Manson, J.E., Hu, F.B., Willett, W.C., Schernhammer, E.S. and Bhupathiraju, S.N. (2018) Rotating Night Shift Work and Adherence to Unhealthy Lifestyle in Predicting Risk of Type 2 Diabetes: Results from Two Large US Cohorts of Female Nurses. BMJ, 21, 363.

https://doi.org/10.1136/bmj.k4641

[13] Strohmaier, S., Devore, E.E., Zhang, Y. and Schernhammer, E.S. (2018) A Review of Data of Findings on Night Shift Work and the Development of DM and CVD Events: A Synthesis of the Proposed Molecular Mechanisms. Current Diabetes Reports, 18, Article No, 132. https://doi.org/10.1007/s11892-018-1102-5

[14] Szkiela, M., Kusideł, E., Makowiec-Dąbrowska, T. and Kaleta, D. (2020) Night Shift Work-A Risk Factor for Breast Cancer. International Journal of Environmental Research and Public Health, 17, 659. https://doi.org/10.3390/ijerph17020659

[15] Yuan, X., Zhu, C., Wang, M., Mo, F., Du, W. and Ma, X. (2018) Night Shift Work Increases the Risks of Multiple Primary Cancers in Women: A Systematic Review and Meta-Analysis of 61 Articles. Cancer Epidemiology and Prevention Biomarkers, 27, 25-40. https://doi.org/10.1158/1055-9965.EPI-17-0221

[16] Khan, W.A., Conduit, R., Kennedy, G.A., Abdullah Alslamah, A., Ahmad Alsuwayeh, M. and Jackson, M.L. (2020) Sleep and Mental Health among Paramedics from Australia and Saudi Arabia: A Comparison Study. Clocks \& Sleep, 2, 246-257. https://doi.org/10.3390/clockssleep2020019

[17] Vetter, C., Fischer, D., Matera, J.L. and Roenneberg, T. (2015) Aligning Work and Circadian Time in Shift Workers Improves Sleep and Reduces Circadian Disruption. Current Biology, 25, 907-911. https://doi.org/10.1016/j.cub.2015.01.064

[18] Dehring, T., Von Treuer, K. and Redley, B. (2018) The Impact of Shift Work and Organisational Climate on Nurse Health: A Cross-Sectional Study. BMC Health Services Research, 18, Article No. 586. https://doi.org/10.1186/s12913-018-3402-5

[19] Alsharari, A.F., Abuadas, F.H., Hakami, M.N., Darraj, A.A. and Hakami, M.W. (2021) Impact of Night Shift Rotations on Nursing Performance and Patient Safety: A Cross-Sectional Study. Nursing Open, 8, 1479-1488.

https://doi.org/10.1002/nop2.766

[20] Yu, T. and Richardson, J.C. (2015) An Exploratory Factor Analysis and Reliability Analysis of the Student Online Learning Readiness (SOLR) Instrument. Online Learning, 19, 120-141. https://doi.org/10.24059/olj.v19i5.593

[21] O'connor, B.P. (2000) SPSS and SAS Programs for Determining the Number of Components USING Parallel Analysis and Velicer's MAP Test. Behavior Research Methods, Instruments, \& Computers, 32, 396-402.

https://doi.org/10.3758/BF03200807 
[22] Gerolimatos, L.A., Gould, C.E. and Edelstein, B.A. (2012) Exploratory Factor Analysis of the Anxiety Control Questionnaire among Older Adults. Behavior Modification, 36, 600-616. https://doi.org/10.1177/0145445512443982

[23] Grzywacz, J.G. (2016) Shift Work and Its Implications for Everyday Work and Family Life: A Foundation and Summary. In: Iskra-Golec, I., Barnes-Farrell, J. and Bohle, P., Eds., Social and Family Issues in Shift Work and Non Standard Working Hours, Springer, Cham, 3-17. https://doi.org/10.1007/978-3-319-42286-2_1

[24] Iskra-Golec, I., Smith, L., Wilczek-Rużyczka, E., Siemiginowska, P. and Wątroba, J. (2017) Shift Schedule, Work-Family Relationships, Marital Communication, Job Satisfaction and Health among Transport Service Shift Workers. International Journal of Occupational Medicine and Environmental Health, 30, 121-131. https://doi.org/10.13075/ijomeh.1896.00670

[25] Mehmood, A., Rowther, A.A., Kobusingye, O. and Hyder, A.A. (2018) Assessment of Pre-Hospital Emergency Medical Services in Low-Income Settings Using a Health Systems Approach. International Journal of Emergency Medicine, 11, Article No. 53. https://doi.org/10.1186/s12245-018-0207-6 